\title{
Desafios dos processos de organização de ensino para a formação das crianças da classe trabalhadora ${ }^{1}$
}

\author{
Challenges of teaching organization processes for the formation of \\ working-class children
}

\author{
Maria Isabel Batista Serrão ${ }^{2}$ \\ Graziela Regina dos Santos ${ }^{3}$
}

\begin{abstract}
RESUMO
O presente texto busca refletir sobre a organização do ensino na perspectiva da Teoria histórico-cultural, particularmente da Atividade Orientadora de Ensino, como modo geral de organização do ensino para o desenvolvimento humano. A sociedade capitalista impõe muitos limites para a formação das melhores qualidades humanas, mas a escola pode ser o lugar privilegiado para a educação como humanização da criança, especialmente a da classe trabalhadora. A partir de estudos e reflexão sobre documentação pedagógica, muitos desafios se apresentam: a professora ou o professor necessita prementemente compreender como a criança aprende, suas reais condições de vida, o movimento lógico e histórico dos conceitos, a importância da apropriação do conhecimento teórico e suas implicações pedagógicas para a organização do ensino que promove o desenvolvimento humano.
\end{abstract}

Palavras-chave: Atividade Orientadora de Ensino. Teoria histórico-cultural. Aprendizagem.

\begin{abstract}
This text aims at presenting elements for the reflection of the organization of teaching based on the Historical-Cultural Theory, particularly the Teaching-Orienteering Activity, as a general way of organizing teaching for human development. Capitalist society imposes many limits on the development of the best human qualities, but the school can be the privileged place for education as humanization of children, especially those belonging in the working class. Based on studies and pedagogical documentation, many challenges are presented: the teacher must have a deep understanding of how children learn, their real life conditions, the logical and historical movement of the concepts, the importance of the appropriation of theoretical knowledge and its pedagogical implications for the organization of the teaching that promotes human development.
\end{abstract}

Keys words: Teaching-Orienteering Activity. Historical-Cultural Theory. Learning.

\footnotetext{
1 Parte do que será exposto neste texto deriva da pesquisa realizada por Santos (2016), cujos desdobramentos orientaram a organização do ensino em uma escola pública, geraram um conjunto de registros escritos e audiovisuais que se constituiu em uma Documentação Pedagógica, bem como a continuidade de estudos sobre atividade pedagógica. Também agradecemos especialmente as valiosas leituras de Carolina Picchetti Nascimento e Josélia Euzébio da Rosa.

2 Doutora em Educação, Membro dos Grupos de Estudos e Pesquisas sobre a Atividade Pedagógica - GEPAPe, Universidade de São Paulo e sobre Infância, Educação e Escola GEPIEE, Universidade Federal de Santa Catarina. ORCID: https://orcid.org/0000-0003-40953845. E-mail: belserrao2@gmail.com.

${ }^{3}$ Mestre em Educação, professora da rede pública de ensino de São José, Santa Catarina. ORCID: https://orcid.org/0000-0001-9537-7246. E-mail: grazielareginasantos@hotmail.com.
} 


\section{Introdução}

Vivemos em uma sociedade formada por classes sociais com interesses claramente antagônicos, perceptíveis especialmente na presente conjuntura histórica. Em linhas gerais, uma formação social constituída por uma classe capitalista que detém a propriedade dos meios de produção da vida e outra, a classe trabalhadora, dividida por várias camadas e formada por pessoas cuja a única propriedade que possuem é a sua força de trabalho. A parcela dessa classe que vende sua força de trabalho para a classe capitalista, ao fazê-lo, produz um valor novo. Parte desse valor corresponde ao valor da força de trabalho e outra é concernente à mais valia, apropriada pela classe capitalista. Assim, sem trabalho humano não há produção de valor, tampouco de mais valia e, portanto, a manutenção das relações sociais capitalistas de produção4.

A garantia de condições para a produção e reprodução da vida humana digna na sociedade capitalista não é reconhecida como um direito social inalienável. Milhares de pessoas estão morrendo pela degradação das condições de vida; pela ação criminosa frente aos movimentos sociais, povos originários, povos da floresta, à natureza e ao perigo da COVID 19; pela violência do Estado, especialmente por meio da atuação coercitiva e homicida da polícia e milícias. No Brasil, a maioria é negra e oriunda de famílias empobrecidas da classe trabalhadora ${ }^{5}$. Como produzir a existência diante da precarização das relações trabalhistas, desemprego, fome, acirramento da desigualdade das condições sociais, do racismo e destruição da natureza?

Teremos que percorrer um longo caminho para criar coletivamente as condições objetivas e subjetivas para a superação das determinações históricas e sociais dessa sociedade do capital. Nesse processo, a apropriação do conhecimento pode oferecer instrumentos teóricos à classe trabalhadora para que se torne capaz de se perceber como parte da história da humanidade, compreendendo as relações que estruturam

\footnotetext{
${ }^{4}$ Sobre as relações sociais capitalistas de produção, ver MARX (1983) e sobre as relações entre Capital, Trabalho e Educação, sugerimos a leitura de TUMOLO (2016).

5 Há muito o que consultar, mas a seguinte matéria é um exemplo a ser visto https://noticias.uol.com.br/saude/ultimas-noticias/redacao/2020/05/19/negros-e-pardos-ja-saomaioria-entre-as-vitimas-fatais-por-covid-19.htm.
} 
essa sociedade, a necessidade da organização coletiva para reivindicar seus direitos e criar possibilidades de intervir na realidade, vislumbrando novos horizontes políticos e econômicos, em que a vida plena de sentido seja produzida e valorizada.

Concordamos com Iasi (2013), ao entender que

é essencial que a classe crie seus próprios espaços formativos, pois não é verdade que o conhecimento considerado como neutro nos ajude em nossas tarefas pelo simples fato de ser conhecimento humano acumulado bastando socializá-lo. O conhecimento é revestido de ideologia, direcionado para uma funcionalidade de reprodução e garantia da ordem. Os trabalhadores, na imagem gramsciana, devem fazer seu inventário, resgatar do conhecimento universal mais desenvolvido as bases para a constituição de sua autonomia de classe, desvelando os fundamentos políticos e os interesses de classe que perpassam o conhecimento e as formas educativas, esta é uma tarefa que passa pela socialização dos conhecimentos nos espaços formais, mas que exige que saibamos construir nossos próprios espaços formativos, pois certos temas e formas educativas exigem espaços próprios e independentes. (IASI, 2013, p.79-80).

Aqui se afirma a relevância social, política, científica e educativa em que se insere a defesa da organização do ensino, considerando a escola como a instituição voltada à formação da criança, prole da classe trabalhadora. A defesa da escola pública não se consolida em si mesma, mas como um dos instrumentos de luta de classe para a socialização do legado produzido historicamente para essas crianças, que não possuem outro local que promova a apropriação de modo sistematizado dos conhecimentos que podem servir de base formativa na construção da consciência de classe ${ }^{6}$ e, consequentemente, a criação coletiva de espaços de formação que se diferem dos formais.

É certo que a história da escola indica sua conformação à ordem social estabelecida, segundo nos ensinou principalmente Cambi (1999), Charlot (1979) e Tragtenberg (2004), e que as condições do trabalho docente nas escolas públicas estão dia a dia em estágios mais elevados de precarização. Isso nos mostra o quanto é difícil essa tarefa! Além disso, quando a educação escolar está voltada às crianças da classe trabalhadora, esse desafio se apresenta ainda maior.

\footnotetext{
${ }^{6}$ Sobre a consciência de classe, ver especialmente IASI (2008). 


\section{Educação, infância, escola e criança}

Concordamos com Leontiev (1978), ao afirmar que

as aquisições do desenvolvimento histórico das aptidões humanas não são simplesmente dadas aos homens nos fenómenos objectivos da cultura material e espiritual que os encarnam, mas são aí apenas postas. Para se apropriar destes resultados, para fazer deles as suas aptidões, "os órgãos de sua individualidade", a criança, o ser humano, deve entrar em relação com os fenômenos do mundo circundante através doutros homens, isto é, num processo de comunicação entre eles. Assim, a criança aprende a actividade adequada. Pela sua função, este processo é, portanto, um processo de educação. (LEONTIEV, grifos no original, 1978, p. 272).

Ao concebermos a educação como conjunto de práticas sociais voltadas para a apropriação do legado humano pelas novas gerações, se torna mais evidente a responsabilidade de formar as qualidades humanas necessárias em cada sujeito, para que se possa projetar viver numa sociedade justa e igualitária, conforme Serra (2000). Assim, também a escola passa a ter um importante lugar nesse processo de educação como humanização. A escola pode ser principal lócus de apropriação desse legado, contribuindo e se afirmando como principal instituição de defesa e exercício do direito social da criança à infância. De acordo com Quinteiro (2000), faz-se necessário

[...] compreender o conceito de infância não a partir do estudo da criança, mas a partir da sua condição social, numa perspectiva histórica, permitindo entender a infância como construção cultural que expressa o modo pelo qual as diferentes sociedades organizam a reprodução de suas condições materiais e não materiais de vida e de existência. (2000, p.26).

A criança é o principal sujeito com os quais adultos se relacionam socialmente na escola. Sua condição de classe determinará o conteúdo das relações entre os sujeitos de diferentes atividades, que são aí estabelecidas.

O que determina diretamente o desenvolvimento da psique de uma criança é a sua própria vida e o desenvolvimento dos processos reais desta vida - em outras palavras: o desenvolvimento da atividade da criança, quer a atividade aparente, quer a atividade 
interna. Mas seu desenvolvimento, por sua vez, depende de suas condições reais de vida. (LEONTIEV, 1988, p. 63).

Como todo ser humano, a criança necessita aprender para se formar como tal e professores e professoras, assim as concebendo, podem passar a compreender também a grandiosidade de sua atividade, que é o ensino. O ensino, quando intencionalmente organizado, pode gerar desenvolvimento na criança. Segundo Vigotsky, não é todo ensino que promove o desenvolvimento, mas sim aquele intencionalmente dirigido a esse fim.

O único bom ensino é o que se adianta ao desenvolvimento. (...) a característica essencial da aprendizagem é que engendra a área de desenvolvimento potencial, ou seja, que faz nascer, estimula e ativa na criança um grupo de processos internos de desenvolvimento no âmbito das inter-relações com outros, que na continuação, são absorvidos pelo curso interior de desenvolvimento e se convertem em aquisições internas da criança.

Considerada deste ponto de vista, a aprendizagem não é, em si mesma, desenvolvimento, mas uma correta organização da aprendizagem da criança conduz ao desenvolvimento mental, ativa todo um grupo de processos de desenvolvimento, e esta ativação não poderia produzir-se sem a aprendizagem. Por isso, a aprendizagem é um momento intrinsicamente necessário e universal para que se desenvolvam na criança essas características humanas não-naturais, mas formadas historicamente. (VIGOTSKII, grifos do autor, 1988, p. 114-115).

Portanto, o conteúdo das interrelações estabelecidas entre as crianças e entre os adultos e as crianças/estudantes, por meio da atividade pedagógica escolar, é de fundamental importância, pois podem produzir as condições favoráveis ou não para a promoção do desenvolvimento humano. A unidade entre sentido pessoal e significação social se formará, se os motivos que geram as ações forem relacionados aos objetos das atividades realizadas na escola: ensino, aprendizagem, estudo.

Nos anos iniciais do Ensino Fundamental, as duas atividades principais da criança, aquelas que guiam, promovem seu desenvolvimento humano em um determinado período de existência, conforme Vigotski (2008), Leontiev (1978 e 1988) e Elkonin (1987), devem ser levadas em consideração pelos professores e professoras na organização do ensino. Uma pode gerar a outra: a brincadeira, 
como denomina Vigotski (2008), oferece as bases para a formação da atividade de estudo (DAVIDOV, 1988 e 1999; DAVÍDOV e MARKOVA, 1987). E, se são as reais condições de vida da criança que determinam a aprendizagem e seu desenvolvimento, considerá-las se torna imprescindível na organização do ensino.

Neste processo, a compreensão dos elementos constitutivos que produzem situações pelas quais a criança, como todo ser humano, possa transformar uma atividade principal em outra, pode também se tornar uma necessidade para os professores e professoras que atuam com crianças na educação infantil e anos iniciais do Ensino Fundamental. Assim sendo, poderão organizar o ensino de modo a promover a aprendizagem que impulsionará o desenvolvimento das crianças, ou seja, criar as condições objetivas, apesar dos limites sociais, para que se produzam as condições internas de passagem de uma atividade a outra.

\section{Atividade Orientadora de Ensino: modo geral de organização do ensino}

Nessa perspectiva, quando a atividade a ser realizada for a atividade pedagógica (que se constitui na unidade entre ensino e aprendizagem), o ensino precisa ser organizado com a intencionalidade de criar nas crianças em idade escolar a necessidade de se apropriar do objeto que agora passa a ser teórico, o conhecimento teórico. A proposta teórico-metodológica da Atividade Orientadora de Ensino (MOURA, 1996, 2001 e 2017; MOURA et al 2010 e 2018), com base na Teoria histórico-cultural, busca atender essa necessidade. Os sujeitos da atividade pedagógica, professor ou professora e criança/estudante, mobilizam-se e desencadeiam ações relacionadas à apropriação da produção cultural humana e voltadas ao desenvolvimento humano em suas máximas potencialidades. $\mathrm{O}$ sentido da atividade é formado na medida em que o motivo que impulsiona os sujeitos a agirem coincide com o objeto da atividade que satisfaz uma determinada necessidade: a transformação dos sujeitos por meio do ensino e da apropriação dos conhecimentos teóricos.

A complexidade da relação entre teoria e prática e como esta precisa se constituir como unidade dialética na atividade pedagógica, que envolve a formação das novas gerações com finalidades sociais e políticas, é um desafio 
que ainda precisamos enfrentar. Isto é, o ato de ensinar não deve ser concebido como um ato isolado da realidade social ou apenas como uma aplicabilidade de conteúdos exigidos pelas grades curriculares sem considerar as necessidades e especificidades do ensino e aprendizagem dos sujeitos que se constituem em atividade. É necessário conhecer quais são as principais necessidades da criança em condições reais de produção da sua existência, como aprendem, como ocorre o processo de apropriação dos conhecimentos e as implicações pedagógicas para o seu desenvolvimento.

Moura (2001) elabora o conceito de Atividade Orientadora de Ensino pelas seguintes palavras:

[...] chamamos de atividade orientadora de ensino aquela que se estrutura de modo a permitir que sujeitos interajam, mediados por um conteúdo, negociando significados com o objetivo de solucionar coletivamente uma situação-problema (MOURA 1996). É atividade orientadora porque define os elementos essenciais da ação educativa e respeita a dinâmica das interações que nem sempre chegam a resultados esperados pelo professor. Este estabelece os objetivos, define as ações e elege os instrumentos auxiliares de ensino, porém não detém todo o processo, justamente porque aceita que os sujeitos em interação partilhem significado que se modificam diante do objeto de conhecimento em discussão. (MOURA, 2001, p. 155).

A atividade pedagógica organizada, segundo os princípios teórico metodológicos da Atividade Orientadora de Ensino, abrange situações desencadeadoras de aprendizagem, que podem se expressar por meio de jogos, situações emergentes do cotidiano e de histórias virtuais, que proporcionem a necessidade de apropriação de conhecimentos teóricos para sua realização. As situações desencadeadoras de aprendizagem criam possibilidades de os estudantes se mobilizarem em busca da solução de um problema semelhante ao que a humanidade já se deparou e cuja solução se cristalizou em conceitos e conhecimentos teóricos. Assim, com caráter lúdico, buscam integrar os elementos de historicidade e os nexos internos do conceito (movimento lógico e histórico) a ser estudado e criar uma necessidade de investigação para os estudantes na resolução do problema que, por 
sua vez, contribuirá para a formação de motivos, gerando o desencadear de ações individuais e coletivas no sentido de apreender os conhecimentos produzidos e sistematizados teoricamente. (MOURA et al 2010 e MOURA et al 2018).

A seguir, abordaremos uma singular atividade pedagógica, inspirada por Moura e seus colaboradores (s.d.) ${ }^{7}$, que envolveu diferentes momentos da atividade de ensino de uma professora em relação à aprendizagem de $\operatorname{crianças}^{8}$, a partir da pesquisa de Santos (2016) e da Documentação Pedagógica produzida ao longo de um ano, como desdobramentos de seus estudos.

\subsection{Momentos de ensinar e aprender}

A atividade de ensino realizada ${ }^{9}$ durante 2019 estava dirigida à aprendizagem de crianças com diferentes dinâmicas históricas de aprendizagem e desenvolvimento (VYGOTSKY, 1996; ÁRIAS BEATÓN, 2001), o que caracterizava diferentes níveis de desenvolvimento real e potencial das crianças (VIGOSKI,1996, ÁRIAS BEATÓN, 2005). Ao conhecer aspectos da história de vida dessas crianças, tornaram-se evidentes as suas consequências no processo de socialização das mesmas, que tendia a reproduzir experiências de estigma étnico-racial e ênfase na meritocracia individual, pautada na visão

\footnotetext{
${ }^{7}$ A proposição de atividade de ensino partiu do que foi realizado pedagogicamente e sistematizado no Fascículo Estatística, organizado Moura et al (s.d.), como um dos produtos do projeto de pesquisa em rede "Educação Matemática nos Anos Iniciais do Ensino Fundamental: Princípios e Práticas da Organização do Ensino" (PPOE) viabilizado pelo Programa Observatório da Educação (Obeduc), financiado pela Coordenação de Aperfeiçoamento de Pessoal de Nível Superior (CAPES), fundamentada nos princípios da Atividade Orientadora de Ensino.

${ }^{8}$ Trata-se do que ocorreu pedagogicamente ao longo de 2019 com uma turma de $1^{\circ}$ ano do Ensino Fundamental numa escola pública da rede municipal de São José, SC, envolvendo 24 crianças, sendo quatro com particularidades específicas no processo de aprendizagem, indicadas em laudo médico, uma estudante universitária que participava do Programa Residência Pedagógica, promovido pelo governo federal e uma auxiliar de Educação Especial, que atuava conjuntamente com a professora responsável pela turma.

9 Tal atividade pedagógica foi realizada em dias alternados, considerando o movimento de aprendizagem das crianças; a presença de bolsistas do Programa Residência Pedagógica e a realização de Projetos de Ensino, elaborados coletivamente a partir do estudo de Miranda (1985); Moura et al (2010) e Mello (2010) e as exigências burocráticas de participação em atividades promovidas pela instituição escolar. Assim, diante das circunstâncias institucionais escolares, imprevistos e limites impostos pelas condições históricas da educação pública brasileira, em alguns momentos pode-se esmorecer, mas a persistência pedagógica em exercitar os princípios teóricometodológicos que orientam a atividade pedagógica na perspectiva histórico-cultural se sobrepôs.
} 
idílica de criança. Essa turma expressa singularidades da complexidade da educação na sociedade capitalista, profundamente marcada por desigualdades étnico-raciais, de gênero e de classe. Assim, considerando as informações relacionadas à vivência ${ }^{10}$ e experiência de aprendizagem das crianças, que ora valorizavam a atuação de bom desempenho escolar, ora invisibilizavam o êxito da aprendizagem, especialmente daquelas crianças negras e que apresentavam laudo médico relacionado à aprendizagem escolar, a intencionalidade pedagógica principal da professora foi a de criar situações de ensino que propiciassem igualdade de oportunidade de aprendizagem. O princípio teóricometodológico de que todos e todas eram capazes de aprender e, portanto, se devolverem, era o que orientava as atividades de ensino e de aprendizagem.

A atividade de ensino realizada pela professora, segundo a estrutura da Atividade Orientadora de Ensino, partiu de uma história virtual como Situação Desencadeadora de Aprendizagem, que apresentava um problema referente à necessidade do controle da variabilidade de um fenômeno relacionado a grandezas em diferentes espaços e da apropriação do conhecimento matemático para sua resolução; seleção de instrumentos didáticos específicos; organização de tempos e espaços em momentos pedagógicos para a criação de situações imaginárias e produção de registros, notações e textos referentes ao controle da variabilidade de um fenômeno em determinados espaços e sua comunicação social

Inicialmente a professora organizou um breve momento para produção de inferências sobre o conteúdo referente à história a ser narrada. Por meio do teatro de sombras, utilizando um lençol, projetor e fantoches que representavam os personagens, as crianças ouviram a seguinte história virtual:

\footnotetext{
${ }^{10}$ Segundo Vygotski, "a vivência deve ser entendida como a relação interior da criança como ser humano, com um ou outro momento da realidade". (...) "se tivéssemos que formular uma tese formal, um tanto generalizada, seria correto dizer que o meio determina o desenvolvimento da criança através da vivência de tal meio. Assim, o mais essencial é renunciar aos índices absolutos do meio. A criança é uma parte da situação social, sua relação com o meio e a relação deste com ela se realiza através da vivência e da atividade da própria criança; as forças do meio adquirem significado orientador graças às vivências da criança. Esta circunstância impõe aos investigadores uma profunda análise interna das vivências da criança, isto é, o estudo do meio que se transfere em significante medida ao interior da própria criança e não se reduz ao estudo das condições externas de sua vida". (1996, p.383).
} 


\section{HISTÓRIA VIRTUAL “O ANIVERSÁRIO DO GIGANTE”:}

Era uma vez um Gigante que morava numa floresta com duendes e gnomos que estavam muito animados após participarem do aniversário do Menino Verde. Toda floresta só comentava dessa festa!

Então, o Gigante também resolveu fazer uma festa de aniversário. Ele queria uma festa de arromba, portanto, ninguém poderia ficar de fora! A vontade era tanta, que toda a floresta foi convidada.

A felicidade do Gigante era tão grande que ele decidiu confeccionar lembranças diferentes para os adultos, para os meninos e para as meninas, de forma a agradar particularmente cada um (cada grupo). Mas surge um problema: as vilas da Floresta Encantada eram muito povoadas e ele não conhecia todas as pessoas.

O Gigante, percebendo o problema, ficou preocupado. Como estimar a quantidade de lembrancinhas que deveria fazer para as meninas, para os meninos e para os adultos? Pensou ainda que se faltassem lembrancinhas, alguns convidados ficariam tristes e, ele muito envergonhado. Por outro lado, fazer lembrancinhas a mais também não seria legal, já que teria que gastar mais dinheiro com um consumo desnecessário. O Gigante tem um grande problema para resolver e precisa de ajuda. Como poderemos ajudá-lo? De que forma? ${ }^{11}$

À princípio, as crianças ficaram interessadas em manusear os fantoches e ver de perto o Gigante e os Gnomos, não esboçando interesse em relação ao problema, tampouco ao levantamento de hipóteses para sua resolução. Em seguida, a professora lidando e considerando, de fato, a transição entre os motivos da criança já apropriados e os que queremos que se apropriem, reconstituiu de forma dialogada a problemática, por meio dos mesmos fantoches e do registro no quadro da identificação de cada grupo de personagens convidados, frisando seu enunciado: como estimar a quantidade de lembrancinhas que o Gigante deverá fazer para as meninas, para os meninos e para os adultos, pois não poderia faltar lembrancinhas para nenhum convidado, mas também, fazer lembrancinhas a mais não será legal, já que teria que gastar mais dinheiro com um consumo desnecessário?

O segundo momento ocorreu uma semana depois, por meio de questões formuladas pela professora e as respectivas respostas das crianças, com o objetivo de retomar os fatos que estruturam a história virtual, para obtenção dos dados referentes à identificação das propriedades de cada população, sua distribuição

\footnotetext{
${ }^{11}$ Essa história virtual foi elaborada a partir da apresentada em Moura et al (s.d., p.16).
} 
no espaço e a criação da necessidade de contagem e registro como ferramentas teóricas estatísticas para a resolução do problema apresentado.

O desenvolvimento da percepção e compreensão das relações essenciais da Estatística, no contexto da história virtual, acontece nas ações de observação e análise dos dados da regularidade, por meio de instrumentos de coleta e registro. Com as frequências organizadas numericamente surgirá a necessidade de apresentar a comunicação, que se dará pela construção de tabelas e gráficos. A história virtual pode permitir que a criança vivencie os processos estatísticos de observação, coleta, organização, comunicação e planejamento vinculado ao fenômeno desencadeador de análise. (MOURA et al, s.d., p.14-15)

Em seguida, as crianças foram organizadas em três grupos, recebendo os seguintes materiais: um pedaço de papel pardo; folhas coloridas que representavam as vilas; cola, canetinha, lápis de cor; figura do gigante; quantidades variadas de imagens de gnomos meninos, gnomos meninas e adultos. As imagens se diferenciavam por categorias e no interior das mesmas também havia diferenciação. Por isso, era necessário que as crianças fizessem o cotejamento da imagem que receberam com as do quadro para saberem como agrupá-las, segundo os critérios estabelecidos a partir dos atributos comuns entre personagens.

As ações que cada grupo foi orientado a realizar foram as seguintes: a) Organizar o espaço de modo que fosse possível o acesso do papel pardo a todos e todas do grupo de crianças; b) Organizar e agrupar as imagens por categoria de gnomos meninos, meninas e adultos, apoiando-se nas imagens afixadas no quadro; c) Colorir as imagens; d) Distribuir a quantidade de gnomos meninos, meninas e adultos pelas vilas. Todas as vilas teriam que ter uma quantidade específica de personagens de cada um desses grupos, objetivando a quantidade da população de cada vila; e) Organizar essas imagens sobre as folhas coloridas, quantificando e classificando os personagens em cada vila e escrevendo o nome destas. Aqui o uso das folhas coloridas e a necessidade de identificar cada vila possibilitou que as crianças operassem com as informações estatísticas, identificando o espaço e frequência populacional de cada vila. Nestas ações as crianças distribuíram sobre o papel a quantidade respectiva de imagens dos personagens de cada categoria em cada vila, estabelecendo os nexos entre 
as informações necessárias para resolução do problema. Em seguida, foi evidenciada a necessidade de registrar por escrito a identificação de cada categoria e a quantidade populacional correspondente em cada vila. Inicialmente as crianças organizaram as imagens de modo aleatório na folha de papel, não perceberam que poderiam utilizar linhas e colunas para melhor identificá-las, quantificá-las e, portanto, registrar de forma adequada estatisticamente o movimento das quantidades; f) Após o questionamento da professora sobre quais seriam atributos comuns dos personagens (propriedades) e se eles poderiam ser utilizados como critérios para agrupá-los e como poderiam fazer para quantificá-los, a necessidade da utilização de linhas e colunas foi evidenciada. Assim, passaram a operar com as informações, identificaram a população, realizaram a contagem segundo as propriedades de cada categoria (adultos, meninos e meninas). Uma criança rapidamente estabeleceu a relação com uma forma específica de registro de informações sobre o movimento de quantidades com variáveis no espaço sob a forma de tabelas já utilizada no cotidiano escolar para o registro da frequência das crianças em aula e o calendário. Isso desencadeou as ações de contagem, registro do subtotal por vila e categoria, contagem, adição e em seguida o registro do universo total, o número total de Gnomos meninos, meninas e adultos que povoam todas as vilas; g) Por fim, a partir do que foi produzido, cada grupo organizou a comunicação oral para a turma, permitindo que todas as crianças pudessem conhecer o que cada grupo produziu e se percebessem capazes, apesar do protagonismo de algumas crianças em detrimento de outras.

Em um terceiro momento uma nova situação imaginária é criada: as crianças receberam uma caixa, contendo uma carta e outros objetos, enviada pelo Gigante, com o objetivo de alimentar o imaginário das crianças e oferecer outros instrumentos que contribuíssem para a apropriação do conhecimento matemático necessário à superação do problema e auxiliassem a comunicação do resultado a que se chegou. Quando as crianças entraram na sala, organizada com figuras de pegadas no chão representando os pés do Gigante e que indicavam na direção do local onde estava a caixa, logo perceberam tais pegadas, identificaram-nas e as seguiram. Nesse momento, a atenção das crianças estava voltada a brincar de 
pular de pegada em pegada até o destino. Elas brincaram de forma organizada, um esperando a vez do outro. O desafio era pular com os dois pés nas pegadas que estavam com certa distância uma da outra. Novamente respeitando a transição dos motivos da aprendizagem das crianças, após este momento, o objetivo da situação desencadeadora de aprendizagem relacionada ao conhecimento matemático (estatística) foi retomado pela professora e a atenção das crianças foi direcionada para a caixa que estava sobre a estante ao fundo da sala. Com a ajuda de uma criança, intencionalmente escolhida pela professora para protagonizar esse momento, como forma de valorizar sua atuação devido às situações de exclusão observadas em outros momentos, a caixa foi colocada no centro da roda formada pelas crianças sentadas. Após o levantamento de hipóteses das crianças a respeito do remetente e do conteúdo da caixa, esta foi aberta e revelado seu conteúdo: material dourado (para auxílio na contagem); imagens dos gnomos; palitos de picolé; folhas de árvores (caracterizando o contexto de onde a caixa foi enviada, a Floresta Encantada) e uma carta do Gigante com o seguinte teor:

Olá crianças da turma 16, tudo bem?

Eu sou o gigante, aquele que vocês estão tentando ajudar a resolver o problema de quantificar as lembrancinhas que preciso confeccionar para cada convidado da minha festa de aniversário, lembram?

Então, cada vez que alguma criança ou adulto conta a minha história e tenta elaborar soluções para me ajudar, uma sirene toca aqui na Floresta Encantada, local em que vivo. Foi assim que cheguei até vocês!

Tenho certeza de que vão conseguir me ajudar!

Mas lembrem-se de que todos os convidados devem levar uma lembrança específica: gnomos adultos, meninos e meninas.

Vocês vão me ajudar?

Envio junto a esta carta materiais que podem ajudá-los na missão de me ajudar, está bom? 
Aguardo uma carta de vocês me contando como faço para quantificar os gnomos, ok?

Até, Gigante (Documentação Pedagógica, 2019, p.10)

Em um quarto momento, após a leitura da carta por uma criança, buscouse organizar os dados obtidos por meio da quantificação do total da população de gnomos de cada categoria em forma de gráfico. A professora solicitou a um dos grupos que explicassem, por meio do cartaz produzido anteriormente, o que o Gigante poderia fazer para saber a quantidade de lembrancinhas que deveria fazer. A partir da observação e análise do conteúdo da produção das crianças, da carta e das características dos materiais enviados, foi indagado às crianças como poderiam utilizar aqueles materiais para resolver o problema apresentado. Neste processo, as crianças chegaram à conclusão de que para ajudar o Gigante tinham que saber a quantidade de Gnomos adultos, meninos e meninas em cada Vila da Floresta Encantada. Assim se tornou clara a necessidade do registro da quantidade estimada para evitar o desperdício ou o fato de algum convidado ficar sem lembrança. Mas como produzir esse registro?

Com o objetivo de proporcionar situações em que as crianças pudessem utilizar mais instrumentos que as auxiliassem no movimento de apropriação do conhecimento matemático, a professora afixou em um lado do quadro um dos cartazes produzidos pelas crianças e de outro um cartaz colorido contendo um gráfico referente à preferência de um grupo de crianças relacionada às frutas que mais gostam. Foi perguntado quem conseguiria fazer a leitura daquele cartaz ou explicá-lo. Logo perceberam, a partir da leitura do enunciado, que se referia à quantificação das frutas relacionadas a uma pesquisa realizada numa turma sobre a fruta que mais gostam.

Diante isso, a professora indagou sobre o que poderiam fazer e que materiais poderiam serem utilizados para organizar os dados referentes à frequência populacional (quantidade total de cada grupo de gnomos) para que o Gigante pudesse entender a explicação. Disseram que poderiam utilizar os palitos para representar a quantidade de gnomos. Buscando atender pedagogicamente 
todas as crianças, a professora estabeleceu um diálogo com elas e identificou suas necessidades formativas por meio das formulações orais que apresentavam indícios do movimento do pensamento das crianças. Assim, evidenciando a necessidade de organizar numericamente a frequência, desenhou no quadro uma representação dos palitos formando um gráfico. $\mathrm{Na}$ continuidade as ações foram realizadas nos mesmos grupos formados anteriormente. Em vários momentos foi necessário enunciar novamente o problema, relembrar as ações já realizadas a partir dos registros produzidos pelas crianças de cada grupo e as respectivas soluções encontradas. Nesse momento se tornou evidente a contribuição de cada grupo para a realização da atividade coletiva de auxílio ao personagem e a formulação da síntese teórica relacionada ao conhecimento matemático, dois dos principais elementos propostos pela Atividade Orientadora de Ensino.

Os grupos de crianças foram organizados com a intencionalidade de assegurar a participação e a aprendizagem efetiva de todas, bem como viabilizar o acompanhamento pedagógico de cada grupo e a atuação específica da professora de acordo com as diferentes necessidades formativas de cada criança. Assim pode-se perceber que o ritmo na resolução da situação problema foi compatível ao repertório cultural apresentado e apropriado, o que desmistificou a ideia de homogeneidade na aprendizagem, ao mesmo tempo em que era valorizada cada iniciativa de resolução formulada, um grupo aprendia com o outro e cada criança se sentia respeitada e responsável por seu próprio movimento de aprendizagem e pelo o do outro. Dois grupos atribuíram uma cor diferente para cada categoria de gnomos e coloriram a quantidade de palitos conforme a quantidade correspondente.

O grupo formado por crianças já alfabetizadas escreveram as palavras que indicavam cada categoria em cada um dos palitos, formando assim três conjuntos de palitos. Nesse grupo específico, formado por meninas e meninos, ao organizarem suas ações para a resolução do problema desencadeador 
explicitaram conflitos referentes à sociabilidade de cunho étnico-racial ${ }^{12} \mathrm{e}$ de gênero, como já haviam vivenciado em outros momentos na escola, dentro e fora da sala de aula. O grupo se subdividiu em meninos e meninas, excluindo uma das meninas. Essa menina negra foi a única que rapidamente estabeleceu a relação com uma forma específica de registro de informações sobre o movimento de quantidades com variáveis no tempo e no espaço sob a forma de tabela, instrumento já utilizado no cotidiano escolar para o registro da frequência das crianças em aula e no calendário. Isso possibilitou que ela passasse a estabelecer também relações aritméticas, operando com parcelas na adição e com as relações essenciais da estatística, em especial: movimento de variabilidade de um fenômeno em determinado espaço; percepção e observação da frequência de um fenômeno; demonstração de regularidade (MOURA et al, s.d., p.25). Enquanto isso, as demais crianças realizavam a pintura dos palitos recebidos como forma de identificação de cada uma das categorias de personagens, instrumentos que seriam utilizados posteriormente para a elaboração de um gráfico. O subgrupo de meninos reclamou da divisão de tarefas, uma vez que o subgrupo das meninas deliberava sobre o que eles tinham que fazer, mas não aceitava o inverso. A quantidade de palitos a serem coloridos era correspondente à quantidade populacional obtida pela tabela produzida pela criança mencionada acima. A relevância dos temas pedagógicos apresentados aqui evidencia a gama de elementos teóricos e políticos que devem ser considerados na organização do ensino, em especial que infância é determinada pelas condições reais de vida das crianças, gênero e etnia ${ }^{13}$. Assim, com o objetivo político e pedagógico de promover as melhores condições de humanização do ser criança na escola, a professora orientou sua atuação nesse e em outros momentos do ensino.

A continuidade do movimento de resolução do problema se deu na sala de aula com as crianças organizadas em roda com os seguintes materiais no centro: Papel

\footnotetext{
${ }^{12}$ Como há uma vasta bibliografia sobre esse importante tema, sugerimos MUNANGA (2005) e BENTO (2012) como roteiro de estudos, pois trazem contribuições de diversos autores sobre vários aspectos referente ao tema.

${ }^{13}$ É premente e fundamental a análise das relações entre classe, gênero, etnia e educação como humanização, pois na imposição dos limites desse artigo, infelizmente, não será possível.
} 
pardo; Imagem do Gigante colorida; Figuras representando os balões; Imagens dos Gnomos adultos, meninas e meninos; Folhas coloridas e cola. Nesse momento a história foi retomada de forma dialogada e com o uso das imagens para reconstituir a narrativa e evidenciar o problema. Reconstituído o problema referente à variabilidade do fenômeno no espaço para conhecer a população, as crianças sugeriram que as figuras fossem agrupadas, coladas uma ao lado da outra, conforme a propriedade de cada gnomo e em cada linha fosse escrita uma palavra que identificasse cada um dos grupos de gnomos respectivos. Iniciou-se com figuras referentes a uma categoria que eram distribuídas em espaços diferentes, identificados no cartaz que correspondiam à representação de cada vila. Um em cada vila a cada rodada, até se esgotar a quantidade de figuras correspondentes ao universo total da população da Floresta Encantada. As crianças também escreveram as palavras adultos, meninos e meninas para identificação de cada grupo.

A escrita das palavras foi realizada com a modelagem e com apoio visual do alfabeto afixado na parede;

A quantificação dos gnomos ocorreu um a um com mediação direta para que a criança continuasse a contar passando seus olhos de uma vila para outra e até chegar a formar o universo total da população referente a cada categoria de gnomo;

Em seguida, solicitava-se que a criança pegasse a quantidade de palitos correspondente à quantidade de gnomos específicos. Por fim, palitos eram colados embaixo da respectiva palavra que identificava a categoria. (Documentação Pedagógica, 2019, p. 21).

Desse modo, pôde-se concluir a elaboração do gráfico e produzir a organização das informações necessárias e, de posse desses conhecimentos, chegar à resolução do problema. Mas ainda havia mais uma tarefa a ser concluída: a comunicação do resultado a que se chegou e, com os conhecimentos apropriados, oferecer contribuições (elementos teóricos) para o Gigante também conhecer como o problema foi solucionado e aprender a solucioná-lo. Nesse momento realizou-se uma exposição oral e dialogada com as crianças a partir dos elementos estruturantes da história virtual, com ênfase no problema, nas ações realizadas para sua solução e nos conhecimentos matemáticos envolvidos. A forma como foi estruturada a atividade pedagógica possibilitou às crianças 
reconstituírem de modo consciente ações referentes à resolução do problema no movimento de aprendizagem do conhecimento matemático e perceberem a necessidade da escrita de uma carta ao Gigante.

Embora o objeto da situação desencadeadora pela história virtual fosse o conhecimento matemático, a aprendizagem das crianças, em especial nos anos iniciais da educação básica, abrange necessariamente o estabelecimento de relações e apropriação de conhecimentos referentes a diversas disciplinas. Portanto, se era necessária a comunicação, foram desencadeadas ações para a produção textual: carta ao Gigante. Cada grupo, de acordo com seu repertório cultural e nível de desenvolvimento real, realizou os procedimentos que contaram com a ajuda do "outro mais experiente", que em alguns casos foram as próprias crianças e em outros os adultos envolvidos na atividade pedagógica. No grupo de crianças alfabetizadas, a atuação da professora ocorreu com a intencionalidade pedagógica de criar situações de ensino para ampliar o repertório cultural referente às características macro estruturais da produção desse texto específico (carta), à estrutura sintática das frases; à escrita ortográfica, à ampliação do vocabulário, bem como para produzir a síntese teórica do conhecimento matemático a ser comunicado, contribuindo, desse modo, para a formação do pensamento teórico. Para o outro grupo, que era formado também por crianças, denominadas pela legislação da educação especial em vigor como "pessoas com deficiência”, foram organizadas tarefas referentes à modelação objetal da escrita (LOPES HURTADO \& BORGATO ANGELETTI, 1995 e UMBELINO, 2014,) especialmente para aqueles já conseguiam realizá-las sem auxílio do outro. A atividade pedagógica organizada dessa forma, considerando as necessidades formativas de aprendizagem de cada grupo de crianças, viabilizou a atuação da professora nos demais grupos. Em um terceiro grupo, a mediação pedagógica para a elaboração da carta foi inicialmente realizada em conjunto com apoio de materiais diversificados (alfabeto móvel e fichas de madeira contendo silábicas diversas); pela vocalização das palavras que as crianças desejavam escrever com ênfase fonética, de modo a discriminar cada componente da palavra e cada 
palavra na frase; ações com objetos materiais e simbólicos que auxiliavam na escrita da palavra e na produção textual. Esses processos proporcionaram às crianças elementos para formar conscientemente a unidade entre forma $\mathrm{e}$ conteúdo do que seria escrito ao destinatário, apropriando-se inicialmente da escrita, da estrutura de uma carta e de sua função social. Segundo Vigotski,

a aprendizagem da escrita é uma das matérias mais importantes da aprendizagem escolar em pleno início da escola, (...) ela desencadeia para a vida o desenvolvimento de todas as funções que ainda não amadureceram na criança. (VIGOTSKI, 2001, p. 332.)

É preciso realizar perguntas que orientem e ofereçam os instrumentos teóricos necessários à formação do pensamento teórico da criança e da produção escrita na sua função social de comunicação. Isso demanda tempo e ações claramente intencionais, focadas na elaboração oral e escrita da criança, pois ela necessita perceber as diferenças entre a oralidade e a escrita, bem como o que se quer comunicar, no caso, a síntese teórica do conhecimento matemático a que se chegou nesse momento de formação dos motivos da atividade de estudo diante do problema inicialmente apresentado, como um problema de aprendizagem teórico, conforme Rubtsov (1997).

A produção textual de uma criança, fruto da organização do ensino que cria a necessidade de apropriação da escrita como uma atividade complexa, não o meramente o desenho das letras, expressou o movimento entre pensamento e linguagem, conforme nos ensinou Vygotski (1993 e 1995). O que predomina na escrita é escrever para o outro e não para si, no caso: Comunicar ao destinatário, o gigante (Tililim ${ }^{14}$ ), o resultado da resolução do problema. A carta escrita por uma criança objetiva as relações essenciais do conhecimento matemático apreendidas até aquele momento do desenvolvimento do pensamento teórico da criança e da apropriação da linguagem escrita pela criança, o estabelecimento de uma interlocução com o destinatário e a indicação do caráter mnemônico da

\footnotetext{
${ }^{14} \mathrm{O}$ nome Tililim foi conferido ao gigante em alusão à outra história virtual, já conhecida pelas crianças: Verdim e seus amigos. (Serrão et al. 2012).
} 
escrita, escrever para lembrar. O texto produzido por uma criança de 7 anos plasma o movimento da experiência e das qualidades humanas apropriadas.

Oi Tililim você pode fazer um gráfico para comtificar e dai você vai saber acomtedadade de adultos e meninas e meninos que tem nas vilas vai encada vila com o grafico não esquece do grafico você vai saber a comtideda de adultos e meninas e menino Tililim fizemos um grafico e deu 5 adultos 8 meninas 5 menino Voi o que deu no nosso grafico Tililim. (Documentação Pedagógica, 2019, p. 30)

Ao analisar a documentação pedagógica pode-se constatar que, ainda e especificamente, para contemplar o processo de apropriação do sistema de conceitos relacionados à estatística, seria necessário enfatizar a importância dos títulos nas tabelas; criar outras atividades de ensino, segundo indicado em Moura el al(s.d: p.25), que proporcionem outras situações desencadeadoras relacionadas à comparação de grandezas em diferentes tempos e espaços para produzir estimativas, bem como "a realização de previsões e possibilidades da ocorrência de um fenômeno". Assim, elementos essenciais e a função social do conhecimento matemático, no caso relações estatísticas, poderiam ser apropriados como um sistema conceitual, permitindo a atuação teórica das crianças diante de problemas semelhantes na escola e também em seu cotidiano.

O que foi realizado por meio da atividade pedagógica, organizada segundo os princípios da Atividade Orientadora de Ensino, apresenta indícios de ser um momento inicial da formação da atividade de estudo, segundo Davidov (1999), uma vez que o "caráter criativo e transformador" esteve presente na atuação das crianças e adultos, apesar de não cumprir com o sistema de tarefas tal como proposto pelo autor em outras obras. Contribuiu para a formação de novas necessidades e motivos, bem como para o desenvolvimento da personalidade,

como um sistema hierárquico complexo de planos ou níveis subordinados de reflexo da realidade e de regulação psíquica da atividade do sujeito que funcionam como um todo único presente na solução de tarefas práticas ou mentais, das mais simples às mais complexas. (MELLO, 2007, p. 97). 
A organização do ensino requer do professor ou professora uma atitude permanente de escuta do que a criança fala para identificar as manifestações de indícios de aprendizagem e criar situações de ensino para que a criança seja orientada aos objetos que queremos que se apropriem, superando o pensamento empírico. Nesse movimento novas necessidades de aprendizagem surgem, novos motivos mobilizam a criança em direção ao conhecimento. $\mathrm{O}$ acompanhamento contínuo desse movimento pela professora ou professor permite a organização do ensino que promove o desenvolvimento.

Porque na escola a criança não aprende o que sabe fazer sozinha, mas o que ainda não sabe e lhe vem a ser acessível em colaboração com o professor e sob sua orientação. $\mathrm{O}$ fundamental na aprendizagem é justamente o fato de que a criança aprende o novo (VIGOTSKI, 2001, p. 331).

A Atividade Orientadora de Ensino desestabiliza o que está posto como cultura escolar e cultura da escola instituídas na tradição pedagógica e educacional. (FORQUIN, 1993). A organização do ensino nesta perspectiva, leva em consideração a participação efetiva da criança, a autoria e intencionalidade pedagógica do professor ou professora no planejamento da atividade pedagógica e o reconhecimento de que o conhecimento é uma produção coletiva, histórica e cultural, o que se contrapõe às listas de conteúdos escolares que devem constar no planejamento educacional nos diversos períodos letivos, à restrição da atividade pedagógica circunscrita à sala de aula e à meritocracia individual. $\mathrm{O}$ registro e a avaliação das manifestações do movimento de aprendizagem das crianças por meio do acompanhamento pedagógico contínuo da professora, observações das relações interpessoais, olhar sensível, cuidadoso e reflexivo sobre cada momento da organização do ensino na atividade pedagógica, desde seu planejamento, realização, avaliação, replanejamento, nova atuação, possibilitou a produção de uma documentação pedagógica que viabilizou o estudo longitudinal sobre a aprendizagem e desenvolvimento das crianças e adultos. Também evidenciou o potencial da Atividade Orientadora de Ensino como modo geral de organização do ensino que desenvolve os sujeitos envolvidos na atividade pedagógica (no caso, 
crianças, jovens estudantes universitárias, apesar dos limites do programa residência pedagógica ${ }^{15}$; professoras responsáveis pelo ensino regular das crianças e pela educação especial; demais trabalhadores e trabalhadoras da educação básica na escola e em outras instâncias administrativas da rede municipal, e adultos responsáveis pela educação das crianças fora da escola).

\section{Considerações finais}

A materialização da intencionalidade da atividade de ensino requer necessariamente que inúmeras ações sejam dirigidas a cada gesto, olhar, escolha e utilização de instrumentos adequados, enfim, ações desencadeadas ao fim proposto: criar situações de ensino para que as crianças/estudantes possam aprender as experiências humanas em seu mais elevado grau e pela apropriação das qualidades humanas, ali encarnadas, possam se desenvolver. Nesse movimento, a atividade pedagógica passa ter pleno sentido tanto para o professor ou professora, como para a criança/estudante, uma vez que, segundo Leontiev (1978 e 1981), os motivos gerados impulsionam o desencadear de ações na direção do objeto e objetivos da atividade de ensino e da atividade aprendizagem.

Por fim, nos tristes tempos em que vivemos, durante a pandemia do Coronavírus, o isolamento social provocou que a relação entre a escola e as famílias fosse repensada e fossem criadas inusitadas formas para a continuidade da aprendizagem e do desenvolvimento das crianças. Seguindo os mesmos princípios da Atividade Orientadora de Ensino e acompanhando a mesma turma de crianças em 2020, não obstante as precárias condições de trabalho, a professora passou a orientar os adultos responsáveis por tais crianças, respeitando suas condições sociais, econômicas e culturais, pela internet (apesar

\footnotetext{
15 É válido evidenciar que o Programa Residência Pedagógica se configurou como campo de luta e resistência na efetivação de atividades pedagógicas voltadas à apropriação das melhores qualidades humanas, respeito, compromisso teórico e político com crianças, suas famílias, professores e professoras, sujeitos da escola pública. Travou-se uma verdadeira disputa, por vezes aparentemente oculta, mas evidente nas atitudes e comportamento. Muitos fatores contribuíram para a instalação desse tensionamento, destacando-se a forma de organização do ensino de crianças e adultos com finalidades claras de classe, considerando aspectos das relações étnico-raciais.
} 
dos alarmantes limites da desigualdade também digital), por mensagens de áudio, vídeo e texto, via celular. Embora seja um movimento repleto de dificuldades, ela já possui inúmeros registros que indicam que as crianças se apropriaram conscientemente dos princípios da Atividade Orientadora de Ensino e orientam os adultos nesse mesmo sentido.

A necessária continuidade dos processos de organização de ensino para a formação das crianças da classe trabalhadora, na perspectiva do desenvolvimento da personalidade e da consciência de classe que possibilitem a compreensão e transformação das condições sociais de produção da vida, indica que mais e novos desafios precisam ser enfrentados coletivamente em todas as esferas humanas. Há muito o que estudar e o que fazer na atuação política e pedagógica. Sigamos!

\section{Referências}

BENTO, M. A. S. (org.) Educação Infantil, igualdade racial e diversidade: aspectos políticos, jurídicos, conceituais. São Paulo: Centro de Estudos das Relações de Trabalho e Desigualdades - CEERT, 2012.

http://www.dominiopublico.gov.br/download/texto/me4575.pdf.

CAMBI, F. História da Pedagogia. São Paulo: Editora UNESP, 1999.

CHARLOT, B. A mistificação pedagógica: realidades socias e processos ideológicos na teoria da educação. Rio de Janeiro: Zahar Editores, 1979.

DOCUMENTAÇÃO PEDAGÓGICA. História Virtual: O Aniversário do Gigante. São José, SC, 2019.

DAVÍDOV, V. La enseñanza escolar y el desarrollo psíquico. Moscú: Editorial Progreso, 1988.

DAVÍDOV, V. V. What is real learning activity? In: HEDEGAARD, M. \& LOMPCHER, J. Learning activity and development. Aarhus: Aarhus University Press,1999.

DAVÍDOV, V. \& MARKOVA, A. La concepción de la actividad de estudio de los escolares. In: DAVÍDOV, V. \& SHUARE, M. L a psicología evolutiva y pedagógica en la URSS: Antologia. Moscú: Editorial Progreso, 1987, pp. 316-337. 
ELKONIN, D. Sobre el problema de la periodización del desarrollo psíquico. In: DAVÍDOV, V. \& SHUARE, M. L a psicología evolutiva y pedagógica en la URSS: Antologia. Moscú: Editorial Progreso, 1987, pp. 104-124.

FORQUIN, J. C. Cultura e escola. Porto Alegre: Artes Médicas, 1993.

GARIAS BEATÓN, G. La persona en lo histórico cultural. São Paulo: Linear, 2005.

GARIAS BEATÓN, G. Evaluación y diagnóstico en la educación y desarrollo. São Paulo: Editor Independente Laura Marisa Calejon, 2001.

LÓPEZ HURTADO, J. \& BORGATTO ANGELETTI, A. Formación de la habilidad de análisis sonoro de la palabra en los niños del sexto año de vida. In: SIVERIO GÓMEZ, A. M. et al. Estudio sobre las particularidades del desarrollo del niño preescolar cubano. Ciudad de La Habana: Pueblo y Educación, 1995.

IASI, M. Educação e consciência de classe: desafios estratégicos. Perspectiva, Florianópolis-SC, volume 31, N.1, p.67-83, jan/abril 2013.

IASI, M. Metamorfose da consciência. São Paulo: Expressão Popular, 2008.

LEONTIEV, A. N. Uma contribuição à teoria do desenvolvimento da psique infantil. In: VIGOTSKII, L. S., LURIA, A. R. \& LEONTIEV, A. N. Linguagem, desenvolvimento e aprendizagem. São Paulo: Ícone Editora da Universidade de São Paulo, 1988. pp 59-82.

LEONTIEV, A. N. O desenvolvimento do psiquismo. Lisboa: Livros Horizonte, 1978.

MARX, K. O Capital. São Paulo: Abril Cultural,1983.

MELLO, S. A. Infância e humanização: algumas considerações na perspectiva histórico-cultural. Revista Perspectiva. Florianópolis-SC, volume 25, N.1, pp. 83-104, jan./jun. 2007.

MELLO, S. A. Ensinar e aprender a linguagem escrita na perspectiva da histórico-cultural. Psicologia Política. Vol.10, N.20, pp.329-343, 2010.

MIRANDA, M. G. O processo de socialização na escola: a evolução da condição social da criança. In: LANE, S. \& CODO, W. Psicologia Social: o homem em movimento. São Paulo: Brasiliense, 1985.

MOURA, M. O. A atividade de ensino como unidade formadora. Bolema, Rio Claro, volume 11, número 12, pp. 29-43, 1996. 
MOURA, M. O. A atividade de ensino como ação formadora. In: CASTRO, Amélia Domingues de; CARVALHO, Anna Maria Pessoa de. Ensinar a ensinar: didática para a escola fundamental e média. (pp. 143-162). São Paulo: Pioneira, 2001.

MOURA, M. O. Matemática na Infância. In: MIGUEIS, M. R.; AZEVEDO, M. G. (Org.). Educação Matemática na infância: abordagens e desafios. Vila Nova de Gaia: Gailivro, 2007. p. 39-64.

MOURA, M. O. A objetivação do currículo na atividade pedagógica. Obutchénie. Uberlândia, MG, v.1, n.1, p. 98-128, jan/abril, 2017. DOI:

https://doi.org/10.14393/obv1n1a2017-5.

MOURA, M. O. (Coord.). Controle da variação de quantidades. Atividades de ensino. Oficina Pedagógica de Matemática. São Paulo, USP, 1996.

MOURA, M.O.; ARAÚJO, E.S.; RIBEIRO, F.D.; PANOSSIAN, M.L. \& MORETTI, V.D. A Atividade Orientadora de Ensino como unidade entre ensino e aprendizagem. In: MOURA, Manoel Oriosvaldo de (Org.). A Atividade Pedagógica na Teoria histórico-cultural. Brasília: Liber Livro, 2010.

MOURA, M. O.; ARAUJO, E. S. \& SERRÃO, M.I.B. Atividade orientadora de ensino: fundamentos. Linhas Críticas, Brasília, DF, v.24, p. 411-430, 2018. DOI: https://doi.org/10.26512/lc.v24i0.19817.

MOURA, M. O. de; LOPES, A. R. L. V.; ARAÚJO, E. S. \& CEDRO, W.L. (Organizadores) Atividades para o ensino da Matemática nos anos iniciais da Educação Básica. Volume I Estatística, s.d. Disponível em: http://www.labeduc.fe.usp.br/wp-content/uploads/e-book_livro1Estat\%C3\%ADstica-FINAL16jan2019.pdf.

MUNANGA, K. (org.) Superando o racismo na escola. $2^{\mathrm{a}}$ edição revisada. Brasília: Ministério da Educação, Secretaria de Educação Continuada, Alfabetização e Diversidade, 2005. http://portal.mec.gov.br/secad/arquivos/pdf/racismo escola.pdf.

QUINTEIRO, J. Infância e escola: uma relação marcada por preconceitos. Tese (Doutorado em Educação) - Universidade Estadual de Campinas, São Paulo, 2000.

RUBTSOV, V. A atividade de aprendizado e os problemas referentes à formação do pensamento teórico dos escolares. In: GARNIER, et al. Após Piaget e Vygotsky. Porto Alegre: Artes Médicas, 1997.

SANTOS, G. R. A organização do ensino e as possibilidades de desenvolvimento humano da criança. Dissertação (Mestrado em Educação), Centro de Ciências da Educação, Universidade Federal de Santa Catarina, 2016, 191p. 
SERRA, D. J. G. La calidad en educación. Lima: Juan Brito Editor, 2000.

SERRÃO, M. I. B.; DAMAZIO, A.; ARAUJO, E. S.; ASBAHR, F. S. F.; ROSA, J. E.\& MOURA, M. O. Relações entre educação infantil e conhecimento matemático. In: XVI Encontro de Didática e Práticas de Ensino, Campinas, São Paulo, ENDIPE, 2012.

TRAGTENBERG, M. A escola como organização social complexa. In:

TRAGTENBERG, M. Sobre educação, política e sindicalismo. São Paulo: Editora UNESP, 2004. DOI: https://doi.org/10.7476/9788539303427.

UMBELINO, J. D. Elementos mediadores na atividade pedagógica promotora do desenvolvimento humano na criança: contribuições da educação em Cuba. Tese (Doutorado em Educação), Centro de Ciências da Educação, Universidade Federal de Santa Catarina, 2014. 459p.

TUMOLO, P. S. Capital, trabalho e educação. Florianópolis: Em Debate, 2016.

VIGOTSKI, L. S. A construção do pensamento e da linguagem. São Paulo: Martins Fontes, 2001.

VIGOTSKI, L. S. A brincadeira e seu papel no desenvolvimento psíquico da criança. Revista Virtual de Gestão de Iniciativas Sociais. Volume 8, abril, 2007, publicada em junho de 2008, pp. 23-36.

VIGOTSKII, L. S. Aprendizagem e desenvolvimento intelectual na idade escolar. In: VIGOTSKII, L. S., LURIA, A. R. \& LEONTIEV, A. N. Linguagem, desenvolvimento e aprendizagem. São Paulo: Ícone Editora da Universidade de São Paulo, 1988. pp. 103-117.

VYGOTSKI, L. S. Obras Escogidas. Tomo II. Madrid: Visor, 1993.

VYGOTSKI, L. S. Obras Escogidas. Tomo III. Madrid: Visor, 1995.

VYGOTSKI, L. S. Obras Escogidas. Tomo IV. Madrid: Visor, 1996.

Recebido em junho de 2020.

Aprovado em agosto de 2020. 